\title{
Movimentação vertical do íon potássio em Neossolos Quartzarênicos sob cultivo com cana-de-açúcar
}

\author{
Fernando Ernesto Ucker ${ }^{(1)}$, Alfredo Borges De-Campos ${ }^{(2)}$, \\ Luís Carlos Hernani ${ }^{(3)}$, José Ronaldo de Macêdo $^{(3)}$ e Adoíldo da Silva Melo(3)
}

\begin{abstract}
(1)Universidade Federal de Goiás, Escola de Agronomia, Rodovia Goiânia/Nova Veneza, Caixa Postal 131, CEP 74690-900 Goiânia, GO, Brasil. E-mail: ferucker@gmail.com (2)Universidade Estadual de Campinas, Caixa Postal 6021, CEP 13084-971 Campinas, SP, Brasil. E-mail: acampos@ige.unicamp.br ${ }^{(3)}$ Embrapa Solos, Rua Jardim Botânico, no 1.024, CEP 22460-000 Rio de Janeiro, RJ, Brasil. E-mail: luis.hernani@embrapa.br, jose.ronaldo@embrapa.br, adoildo.melo@embrapa.br
\end{abstract}

Resumo - O objetivo deste trabalho foi determinar a movimentação vertical do íon potássio em perfil de Neossolo Quartzarênico cultivado com cana-de-açúcar. Foram realizados dois experimentos, em campo. O primeiro consistiu de uma avaliação da movimentação do íon no perfil do solo até $1,80 \mathrm{~m}$ de profundidade, por dois anos, em uma área cultivada com cana-de-açúcar e em outra sob cerrado. O segundo consistiu da avaliação do movimento do íon até a profundidade de $1,00 \mathrm{~m}$, sob dois regimes hídricos: natural e controlado. No experimento sob condições controladas, as avaliações foram feitas em parcelas de $0,5 \mathrm{~m}^{2}$, delimitadas por chapas galvanizadas, com adição de $80 \mathrm{~kg} \mathrm{ha}^{-1}$ de $\mathrm{K}_{2} \mathrm{O}$ seguida da adição de $1.200 \mathrm{~mm}$ de água. A área sob lavoura apresentou maior conteúdo de matéria orgânica do solo, maior $\mathrm{pH}$ e, consequentemente, maior capacidade de retenção do $\mathrm{K}^{+}$nas camada superficiais do perfil do que a área de cerrado. Além disso, na área sob lavoura, a avaliação da disponibilidade de $\mathrm{K}^{+}$ao longo do perfil do Neossolo avaliado foi influenciada pelo tipo de regime hídrico adotado (chuva natural ou controlada). Independentemente do uso do solo, o $\mathrm{K}^{+}$ apresenta rápida movimentação no perfil do solo.

Termos para indexação: Saccharum, adubação potássica, capacidade de retenção, lixiviação, solos frágeis, solos leves.

\section{Vertical movement of the potassium ion in Quartzipsamment Entisols under sugarcane crop}

\begin{abstract}
The objective of this work was to determine the vertical movement of the potassium ion in the profile of Quartzipsamment Entisols cultivated with sugarcane. Two experiments were conducted in field conditions. The first one consisted of an assessment of ion movement in the soil profile, down to $1.80-\mathrm{m}$ depth, for two years, in an area cultivated with sugarcane and in another one under cerrado. The second one consisted of the evaluation of ion movement to a depth of $1.00 \mathrm{~m}$, under two water regimes: natural and controlled. In the experiment under controlled conditions, evaluations were done with $0.5-\mathrm{m}^{2}$ plots, delimited by galvanized sheets, receiving $80 \mathrm{~kg} \mathrm{ha}^{-1} \mathrm{~K}_{2} \mathrm{O}$ followed by the addition of 1,200 $\mathrm{mm}$ of water. The area cropped with sugarcane showed greater soil organic matter content, greater $\mathrm{pH}$, and, consequently, greater retention capacity of $\mathrm{K}^{+}$in the superficial layers of the soil profile than the cerrado area. Moreover, in the area with sugarcane crop, the evaluation of $\mathrm{K}^{+}$availability in the profile of the Quartzipsamment Entisol profile was affected by the adopted water regime (natural or controlled rainfall). Regardless of soil use, $\mathrm{K}^{+}$moves rapidly through the soil profile.
\end{abstract}

Index terms: Saccharum, potassium fertilization, retention capacity, leaching, fragile soils, light soils.

\section{Introdução}

Em solos arenosos da região dos cerrados, áreas com pastagens e cultivadas com soja e milho estão cedendo lugar à cultura da cana-de-açúcar (Barbalho et al., 2013). Segundo Cerri et al. (1991) e Govers et al. (1994), mudanças no uso do solo influenciam marcadamente os programas de fertilização e a qualidade e a sustentabilidade dos recursos naturais da região. Assim, o aumento do cultivo da cana-deaçúcar pode aumentar o impacto da atividade agrícola na região, o que torna necessário que se avalie o manejo de fertilizantes agrícolas e que se determine os mais adequados para uso nessa cultura, além de seus possíveis impactos ao meio ambiente, especialmente no que se refere a águas subterrâneas. 
Neossolos Quartzarênicos (RQ) ocorrem em vastas áreas do Cerrado e são considerados ecologicamente frágeis, por apresentarem baixa capacidade de retenção de água e nutrientes, além de elevada erodibilidade (Zuo et al., 2008). Esses solos, quando antropizados, necessitam de um programa rigoroso de aporte de matéria orgânica e nutrientes, para um manejo agrícola sustentável (Carneiro et al., 2009), uma vez que a maior parte de sua capacidade de troca catiônica advém da fração orgânica do solo (Silva \& Miziara, 2011). No Estado de Goiás, estes solos estão sendo utilizados para o plantio de cana-de-açúcar (Silva \& Miziara, 2011). Entretanto, ainda não se conhecem os efeitos que seu uso com a cultura pode ter sobre o movimento do íon potássio ao longo do perfil do solo.

Diversos estudos tratam da movimentação e dinâmica do íon potássio no perfil do solo. Neves et al. (2009) avaliaram o gradiente de concentração de $\mathrm{K}^{+}$a partir da fertilização de cinco tipos de solos, com diferentes doses de cloreto de potássio $(\mathrm{KCl})$, e concluíram que a movimentação vertical do íon se dá de forma rápida. Ernani et al. (2007) avaliaram a movimentação do íon em Cambissolo Húmico e Nitossolo Vermelho, e constataram que o nutriente atinge elevadas profundidades no perfil do solo, sem, contudo, proporcionar grande lixiviação. Werle et al. (2008) estudaram a dinâmica do íon em função do teor de argila e do nutriente no solo, e concluíram que a adubação potássica aumenta as quantidades de percoladas de $\mathrm{K}^{+}$.

Embora seja um assunto relevante, tanto do ponto de vista agrícola como ambiental, não foi encontrado na literatura um estudo que avaliasse em detalhe a movimentação do íon potássio no perfil de Neossolos Quartzarênicos sob cultivo com cana-de-açúcar.

O objetivo desta pesquisa foi verificar a movimentação vertical do íon potássio em um Neossolo Quartzarênico cultivado com cana-de-açúcar em comparação com o mesmo solo sob vegetação de cerrado em estudos desenvolvidos em campo e em condições controladas.

\section{Material e Métodos}

A pesquisa foi realizada em área da Fazenda Araucária, pertencente à empresa BrasilAgro, situada na porção sudoeste do Município de Mineiros, GO, nas coordenadas $17^{\circ} 47^{\prime} 31.15^{\prime \prime S}$ e $53^{\circ} 00^{\prime} 10.04^{\prime \prime O}$. O clima, segundo classificação de Köppen, é caracterizado como tropical chuvoso (Aw), com seis meses de chuvas (novembro a abril) e seis meses sem quantidades expressivas de precipitação (maio a outubro).

Para a avaliação da movimentação vertical do íon potássio no perfil de um Neossolo Quartzarênico sob cultivo de cana-de-açúcar, foram realizados dois experimentos, em campo. O primeiro consistiu de uma avaliação da movimentação do íon até $1,80 \mathrm{~m}$, por dois anos, em uma área cultivada com cana-de-açúcar e em outra sob cerrado. O segundo consistiu da avaliação do movimento do íon até a profundidade de $1,00 \mathrm{~m}$, sob dois regimes hídricos: natural e controlado.

Como tratamentos, foram consideradas duas faixas paralelas: uma com vegetação nativa de cerrado (RQ Cerrado, testemunha) e outra com cultivo de cana-de-açúcar (RQ Lavoura). Em cada uma das faixas, foi estabelecido um transecto com dez pontos de amostragem, espaçados de $30 \mathrm{~m}$ entre si, onde se realizou a coleta de amostras compostas do solo.

Foram coletadas três amostras por ponto, nas duas áreas estudadas, com trado holandês, nas camadas de: $\quad 0,0-0,20, \quad 0,20-0,40, \quad 0,40-0,60, \quad 1,00-1,20$ e $1,60-1,80 \mathrm{~m}$ de profundidade. As coletas ocorreram em novembro de 2011 e novembro de 2012, no início da estação chuvosa na região, e em abril de 2012 e abril de 2013, no final da estação chuvosa. Após a coleta, as amostras foram ensacadas, devidamente identificadas e encaminhadas ao Laboratório de Solos da Embrapa Solos, no Rio de Janeiro, RJ, para análise.

A cana-de-açúcar havia sido plantada em março de 2008, com adubação inicial de $500 \mathrm{~kg}$ da fórmula $\mathrm{N}-\mathrm{P}_{2} \mathrm{O}_{5}-\mathrm{K}_{2} \mathrm{O}$ 05-05-05. Os cortes foram realizados em agosto de 2010, maio de 2011 e agosto de 2012, com produtividades de colmos de 160,140 e $110 \mathrm{Mg} \mathrm{ha}^{-1}$, respectivamente. As adubações ocorreram após cada corte, ou seja, em setembro de 2010, julho de 2011 e outubro de 2012, com a fórmula $\mathrm{N}-\mathrm{P}_{2} \mathrm{O}_{5}-\mathrm{K}_{2} \mathrm{O}$ 18-00-27, nas quantidades de $700 \mathrm{~kg}, 570 \mathrm{~kg}$ e $480 \mathrm{~kg}$, respectivamente.

No experimento com regime hídrico natural, não houve qualquer adição de água ao solo além da precipitação pluvial. Para evitar o possível carreamento de água e nutrientes de fora para dentro da área em estudo, chapas galvanizadas foram confeccionadas para delimitá-la, conforme Ramos (2013). Essas chapas, com altura de $25 \mathrm{~cm}$, foram enterradas $5 \mathrm{~cm}$ no solo. As áreas delimitadas pelas chapas possuíam 
área de $0,5 \mathrm{~m}^{2}$, no formato de um retângulo com $1,0 \mathrm{~m}$ de comprimento e $0,5 \mathrm{~m}$ de largura (Figura 1).

Em novembro de 2013, após a delimitação das áreas de estudo e coleta das amostras testemunhas, a $30 \mathrm{~cm}$ de cada chapa, foi aplicado o equivalente a 80 $\mathrm{kg} \mathrm{ha}^{-1}$ de $\mathrm{K}_{2} \mathrm{O}$, na forma de $\mathrm{KCl}$, no interior de cada uma das áreas delimitadas. Esperou-se, então, o fim do período chuvoso para nova coleta do solo. Em abril de 2014, retornou-se à área e procedeu-se à nova coleta de amostras no interior das áreas com as chapas. Amostras compostas foram coletadas - três por ponto - com trado holandês, nas camadas de $0,0-0,10,0,10-0,20$, $0,20-0,30,0,30-0,40,0,40-0,50,0,50-0,60,0,60-0,70$, $0,70-0,80,0,80-0,90$ e $0,90-1,00 \mathrm{~m}$ de profundidade.
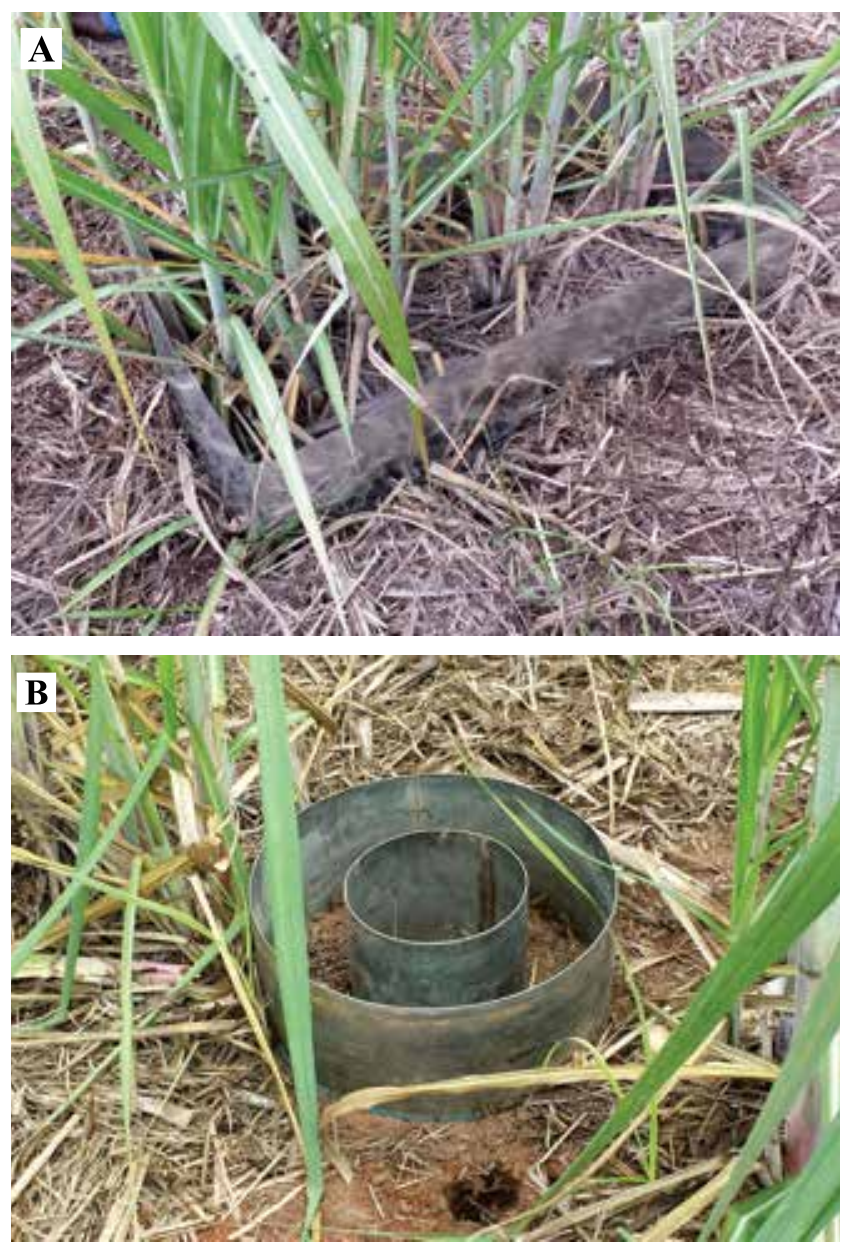

Figura 1. Experimentos realizados sob regime hídrico natural, com calhas (A), e controlado (B), com anéis concêntricos, na área de Neossolo Quartzarênico sob cultivo de cana-de-açúcar.
Sob regime hídrico controlado, foram utilizados três conjuntos de anéis concêntricos (diâmetro do anel externo de $40 \mathrm{~cm}$, e diâmetro do anel interno de $20 \mathrm{~cm}$ ), em cada área estudada (lavoura ou cerrado), conforme a Figura 1. Os anéis concêntricos foram dispostos a cerca de $1,0 \mathrm{~m}$ das calhas metálicas do experimento sob regime hídrico natural. Inicialmente, coletaram-se amostras do solo próximo à área de implantação dos anéis, para que servissem como testemunha $\left(\mathrm{K}_{\text {test }}\right)$. Em seguida, a área interna de cada anel foi saturada com $600 \mathrm{~mm}$ de água. Manteve-se igual nível de água no anel externo. Esperou-se por 24 horas para ocorrer a drenagem e equilíbrio da água no solo e, então, aplicou-se a mesma quantidade de $\mathrm{K}_{2} \mathrm{O}$ utilizada no experimento sob regime natural, no interior do anel interno. Em seguida, novo volume de $600 \mathrm{~mm}$ de água foi aplicado no interior desse anel. Após 48 horas, procedeu-se à coleta do solo (com trado holandês) no interior $\left(\mathrm{K}_{\text {int }}\right)$ e exterior $\left(\mathrm{K}_{\text {ext }}\right)$ do anel interno, bem como na parte externa do anel externo $\left(\mathrm{K}_{\text {fora }}\right)$, conforme Figura 2. As amostras de solo foram coletadas a cada $0,10 \mathrm{~m}$, até a profundidade de $1,00 \mathrm{~m}$.

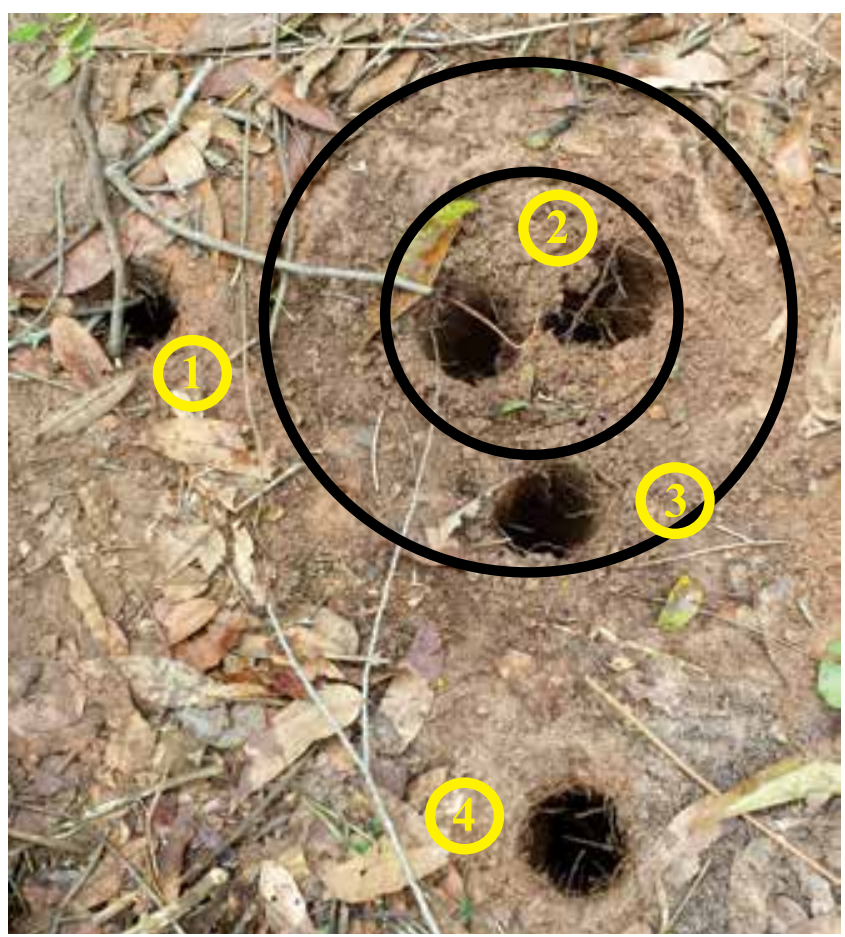

Figura 2. Amostragem de solo nas camadas estudadas sob regime hídrico controlado: 1, amostra testemunha $\left(\mathrm{K}_{\text {test }}\right) ; 2$, amostra na parte interna do anel interno $\left(\mathrm{K}_{\mathrm{int}}\right)$; 3, amostra na parte externa do anel interno $\left(\mathrm{K}_{\mathrm{ext}}\right)$; e 4, amostra fora do anel externo $\left(\mathrm{K}_{\text {fora }}\right)$. 
Nas amostras dos dois experimentos, o íon potássio foi extraído com solução Mehlich-1, na relação solo:extrator 1:5. Seu conteúdo foi determinado em ICP-OES. As demais análises físicas e químicas do solo seguiram os procedimentos descritos por Claessen (1997). As concentrações de $\mathrm{K}^{+}$no solo, nas diversas profundidades, nos diferentes tratamentos, foram comparadas pelo teste $\mathrm{t}$, a $5 \%$ de probabilidade, com auxílio do programa Assistat, na versão Free 7.7 (Silva \& Azevedo, 2009).

\section{Resultados e Discussão}

No primeiro experimento, os teores de $\mathrm{K}^{+}$diminuíram nas camadas superiores do solo $(0,0-0,20 \mathrm{~m}$ e 0,20-0,40 m), no RQ Lavoura, na comparação entre o início (abril de 2012 e abril de 2013) e final do período chuvoso (novembro de 2011 e novembro de 2012). Em contrapartida, esses teores aumentaram nas camadas inferiores do solo, até a camada de 1,60-1,80 m (Tabela 1). Para o RQ Cerrado, no entanto, a mesma tendência não foi observada, e os teores do nutriente, entre os períodos amostrados, mantiveram-se, em geral, inalterados nas camadas superiores, ou diminuíram em profundidade, no final do período chuvoso. Este resultado evidencia a diferença entre os tipos de uso do solo, quanto ao potencial de perdas do nutriente por lixiviação, o qual é acentuado com a implantação do cultivo da cana. Chuvas intensas foram comuns no período de realização do experimento (Figura 3) e devem ter facilitado o transporte do íon potássio para as camadas inferiores do solo ou, ainda, sua perda por escoamento superficial (Padilla et al., 1999) no solo cultivado.

A redução considerável do conteúdo de $\mathrm{K}^{+}$na camada 0,0-0,20 m, no RQ Lavoura (Tabela 1), nas épocas após o período chuvoso (abril), pode ser atribuída ao consumo do nutriente pela cultura da cana-de-açúcar e à movimentação do íon para camadas inferiores do solo. Com a adubação, o KClé depositado na superfície do solo, o que propicia a recuperação de seus conteúdos nas camadas superficiais, conforme verificado nesse estudo no início dos períodos chuvosos.

$\mathrm{O}$ aumento nos teores do íon potássio nas camadas $0,40-0,60,1,00-1,20$ e 1,60-1,80 m, após o período chuvoso, no RQ Lavoura, é preocupante, pois a lixiviação contínua pode contribuir para a contaminação das águas subterrâneas (Meurer et al.,
2000; Oliveira et al., 2000; Lyra et al., 2003; Silva et al., 2007).

A pequena variação no teor do $\mathrm{K}^{+}$, no RQ Cerrado, nas camadas superiores, em todos os períodos de amostragem, pode ser explicada pela incorporação do elemento ao solo por meio da decomposição de resíduos orgânicos depositados pelo cerrado na superfície do solo. A lavagem do íon diretamente das folhas das plantas também pode contribuir para adição do nutriente nas camadas superficiais do solo. Já a redução nos teores de $\mathrm{K}^{+}$nas camadas $1,00-1,20$ e 1,60-1,80 m do RQ Cerrado, na última época amostrada (abril de 2013), pode estar associada, além da extração por parte da vegetação durante o período chuvoso, também à lixiviação do nutriente para camadas ainda mais profundas do solo, promovida pela maior pluviosidade ocorrida no período chuvoso (Figura 3).

O teor de matéria orgânica na área de lavoura de cana-de-açúcar foi maior do que no solo sob cerrado, em todas as épocas avaliadas (Tabela 2). Segundo Frazão et al. (2010), a incorporação de resíduos vegetais após a colheita e a aplicação de corretivos e fertilizantes são fatores que mantêm ou incrementam a matéria orgânica no solo. Este fato reveste-se de grande relevância para os Neossolos Quartzarênicos, tendo em vista sua grande deficiência natural de MO. No RQ Lavoura, a MO pouco diferiu entre as épocas estudadas, o que também ocorreu no RQ Cerrado.

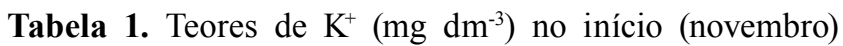
e ao final (abril) do período chuvoso, em Neossolo Quartzarênico sob dois tipos de usos: lavoura de cana-deaçúcar e vegetação de Cerrado.

\begin{tabular}{lrrrr}
\hline Camada (m) & Nov. 2011 & Abr. 2012 & Nov. 2012 & Abr. 2013 \\
\hline \multicolumn{5}{c}{ Lavoura } \\
$0,0-0,20$ & $31,0^{*}$ & 10,4 & $24,1^{*}$ & 11,6 \\
$0,20-0,40$ & $16,2^{*}$ & $10,4 \mathrm{~b}$ & 10,4 & 9,2 \\
$0,40-0,60$ & 7,2 & 10,4 & 7,6 & 9,2 \\
$1,00-1,20$ & 2,8 & 4,8 & $3,2^{*}$ & 6,8 \\
$1,60-1,80$ & 0,8 & 2,8 & 3,2 & 3,8 \\
\hline \multicolumn{5}{c}{ Cerrado } \\
$0,0-0,20$ & $17,8^{*}$ & 23,6 & 20,0 \\
$0,20-0,40$ & 11,6 & 13,5 & 11,6 & 17,1 \\
$0,40-0,60$ & 8,4 & 7,2 & $9,2^{*}$ & 10,4 \\
$1,00-1,20$ & 2,8 & 4,0 & $4,0^{*}$ & 5,2 \\
$1,60-1,80$ & 3,6 & 3,2 & $4,0^{*}$ & 0,0 \\
\hline
\end{tabular}

*Diferença significativa pelo teste $\mathrm{t}$, a $5 \%$ de probabilidade, entre os valores no início (novembro) e ao final (abril) do período chuvoso. 
A elevação da matéria orgânica do solo favorece a capacidade de troca catiônica nos solos (Araújo et al., 2007; Campos et al., 2011), e esse efeito é mais pronunciado para RQs (Frazão et al., 2008; Carneiro et al., 2009), onde a predisposição ao processo de lixiviação de cátions e à perda da MO é maior. Porém, os teores de matéria orgânica e de CTC foram baixos tanto no RQ Lavoura quanto no RQ Cerrado (Tabela 2).

Os valores de $\mathrm{pH}$ foram, em geral, maiores no RQ Lavoura (Tabela 2) do que no RQ Cerrado, em razão da calagem realizada no ano de 2008 , no solo sob cultivo. No entanto, a retenção do potássio nas camadas superficiais do perfil do solo não foi influenciada pelo $\mathrm{pH}$ do solo, o que difere do reportado por Mascarenhas et al. (1988).

No segundo experimento, a aplicação de potássio promoveu expressivo incremento nos teores do nutriente em todas as camadas, sob regime hídrico natural, tanto no RQ Lavoura como no RQ Cerrado (Tabela 3). A semelhança no comportamento dos teores

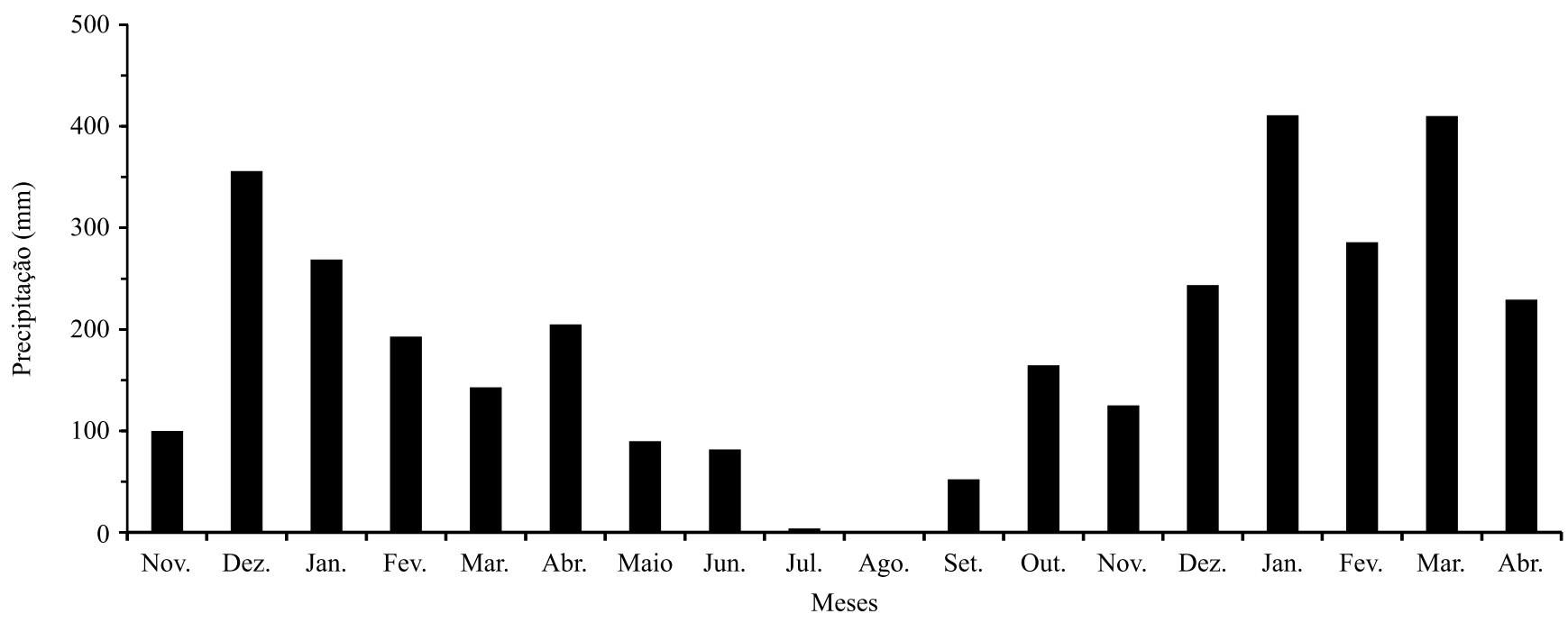

Figura 3. Precipitação ocorrida durante os meses de realização do experimento, em Mineiros, GO, no período 2011-2013.

Tabela 2. Matéria orgânica do solo, capacidade de troca catiônica e pH do solo, em diferentes profundidades, no início (novembro) e ao final (abril) do período chuvoso, em Neossolo Quartzarênico sob dois tipos de usos: lavoura de cana-de-açúcar e vegetação de Cerrado( ${ }^{(1)}$.

\begin{tabular}{|c|c|c|c|c|c|c|c|c|c|c|}
\hline \multirow[t]{2}{*}{ Época } & \multicolumn{5}{|c|}{ Profundidades $(\mathrm{m})$ avaliadas na área de lavoura } & \multicolumn{5}{|c|}{ Profundidades $(\mathrm{m})$ avaliadas na área de Cerrado } \\
\hline & $0,0-0,20$ & $0,20-0,40$ & $0,40-0,60$ & $1,00-1,20$ & $1,60-1,80$ & $0,0-0,20$ & $0,20-0,40$ & $0,40-0,60$ & $1,00-1,20$ & $1,60-1,80$ \\
\hline & \multicolumn{10}{|c|}{ Matéria orgânica do solo $\left(\mathrm{g} \mathrm{dm}^{3}\right)$} \\
\hline Nov. 2011 & $10,4 \mathrm{ab}$ & $6,1 \mathrm{a}$ & $5,0 \mathrm{a}$ & $3,0 \mathrm{a}$ & $2,1 \mathrm{ab}$ & $5,2 \mathrm{ab}$ & $3,0 \mathrm{a}$ & $2,5 \mathrm{a}$ & $1,5 \mathrm{a}$ & $1,0 \mathrm{ab}$ \\
\hline Abr. 2012 & $11,7 \mathrm{a}$ & $5,8 \mathrm{a}$ & $4,3 \mathrm{ab}$ & $2,8 \mathrm{a}$ & $1,9 \mathrm{bc}$ & $5,9 \mathrm{a}$ & $2,9 \mathrm{a}$ & $2,2 \mathrm{ab}$ & $1,4 \mathrm{a}$ & $0,9 \mathrm{bc}$ \\
\hline Nov. 2012 & $9,4 \mathrm{~b}$ & $6,4 a$ & $4,8 \mathrm{ab}$ & $2,9 \mathrm{a}$ & $2,3 \mathrm{a}$ & $4,7 b$ & $3,2 \mathrm{a}$ & $2,4 \mathrm{ab}$ & $1,5 \mathrm{a}$ & $1,1 \mathrm{a}$ \\
\hline \multirow[t]{2}{*}{ Abr. 2013} & $10,1 \mathrm{ab}$ & $5,8 \mathrm{a}$ & $3,9 \mathrm{~b}$ & $2,1 \mathrm{a}$ & $1,6 \mathrm{c}$ & $5,0 \mathrm{ab}$ & $2,9 \mathrm{a}$ & $1,9 \mathrm{~b}$ & $1,1 \mathrm{a}$ & $0,8 \mathrm{c}$ \\
\hline & \multicolumn{10}{|c|}{ Capacidade de troca catiônica $\left(\mathrm{cmol}_{\mathrm{c}} \mathrm{dm}^{3}\right)$} \\
\hline Nov. 2011 & $5,3 b$ & $4,5 \mathrm{a}$ & $3,7 \mathrm{a}$ & $2,5 \mathrm{a}$ & $2,2 \mathrm{a}$ & $5,1 \mathrm{a}$ & $3,9 \mathrm{a}$ & $3,0 \mathrm{ab}$ & $2,1 \mathrm{a}$ & $1,9 \mathrm{ab}$ \\
\hline Abr. 2012 & $5,9 a$ & $3,7 \mathrm{~b}$ & $3,0 \mathrm{~b}$ & $2,2 \mathrm{ab}$ & $1,8 \mathrm{~b}$ & $5,5 \mathrm{a}$ & $3,5 \mathrm{a}$ & $3,0 \mathrm{ab}$ & $2,1 \mathrm{a}$ & $1,6 b$ \\
\hline Nov. 2012 & $5,3 b$ & $3,2 \mathrm{bc}$ & $2,6 b$ & $1,7 \mathrm{c}$ & $1,3 \mathrm{c}$ & $5,1 \mathrm{a}$ & $3,6 \mathrm{a}$ & $3,3 a$ & $2,3 a$ & $2,0 \mathrm{a}$ \\
\hline \multirow[t]{2}{*}{ Abr. 2013} & $5,7 \mathrm{a}$ & $3,9 b$ & $2,5 \mathrm{c}$ & $1,9 \mathrm{bc}$ & $1,4 \mathrm{c}$ & $5,3 a$ & $3,5 \mathrm{a}$ & $2,8 \mathrm{~b}$ & $2,0 \mathrm{a}$ & $1,6 \mathrm{~b}$ \\
\hline & \multicolumn{10}{|c|}{$\mathrm{pH}$} \\
\hline Nov. 2011 & $6,3 a$ & $5,6 a$ & $5,2 \mathrm{a}$ & $4,8 \mathrm{a}$ & $5,0 \mathrm{a}$ & $4,5 \mathrm{a}$ & $4,4 a$ & $4,5 b$ & $5,2 \mathrm{a}$ & $5,3 \mathrm{a}$ \\
\hline Abr. 2012 & $6,1 \mathrm{a}$ & $5,8 \mathrm{a}$ & $5,3 a$ & $4,8 \mathrm{a}$ & $4,9 a$ & $4,6 \mathrm{a}$ & $4,8 \mathrm{a}$ & $4,7 \mathrm{ab}$ & $4,9 b c$ & $4,9 b$ \\
\hline Nov. 2012 & $6,1 \mathrm{a}$ & $5,6 a$ & $5,2 \mathrm{a}$ & $4,8 \mathrm{a}$ & $5,1 \mathrm{a}$ & $4,7 \mathrm{a}$ & $4,9 \mathrm{a}$ & $4,7 \mathrm{ab}$ & $4,8 \mathrm{c}$ & $4,9 b$ \\
\hline Abr. 2013 & $6,2 \mathrm{a}$ & $6,0 \mathrm{a}$ & $5,5 \mathrm{a}$ & $5,1 \mathrm{a}$ & $5,1 \mathrm{a}$ & $4,6 \mathrm{a}$ & $4,8 \mathrm{a}$ & $4,9 a$ & $5,1 \mathrm{ab}$ & $5,2 \mathrm{a}$ \\
\hline
\end{tabular}

${ }^{(1)}$ Médias seguidas de letras iguais, nas colunas, não diferem a 5\% de probabilidade. 
de $\mathrm{K}^{+}$após a fertilização potássica, nos diferentes usos do solo, era esperada e pode ser explicada pela pequena diferença entre os atributos do solo - conteúdos de argila e matéria orgânica - nos diferentes manejos (Tabela 4). Diversos autores encontraram resultados semelhantes (Orlando Filho et al., 1983; Silva et al., 2001; Werle et al., 2008).

Como os teores de $\mathrm{K}^{+}$antes da aplicação do nutriente já eram maiores no RQ Lavoura, os maiores teores após aplicação eram esperados (Tabela 5). A quantidade lixiviada do íon é, segundo Ernani et al. (2003), proporcional à concentração inicial do nutriente na solução no solo - e, indiretamente, ao seu conteúdo

Tabela 3. Valores médios de $\mathrm{K}^{+}\left(\mathrm{mg} \mathrm{dm}^{-3}\right)$ no experimento com regime de chuva natural, no início (novembro) e ao final (abril) do período chuvoso, em Neossolo Quartzarênico sob dois tipos de usos: lavoura de cana-de-açúcar e vegetação de Cerrado.

\begin{tabular}{lccccc}
\hline \multirow{2}{*}{$\begin{array}{l}\text { Camada } \\
(\mathrm{m})\end{array}$} & \multicolumn{2}{c}{ Lavoura } & & \multicolumn{2}{c}{ Cerrado } \\
\cline { 2 - 3 } \cline { 5 - 6 } \cline { 5 - 6 } & Novembro & Abril & & Novembro & Abril \\
\hline $0,0-0,10$ & $40,7^{*}$ & 51,0 & & $19,3^{*}$ & 38,7 \\
$0,10-0,20$ & $24,7^{*}$ & 31,3 & & $14,7^{*}$ & 26,0 \\
$0,20-0,30$ & 20,0 & 26,0 & & $12,0^{*}$ & 21,3 \\
$0,30-0,40$ & $13,3^{*}$ & 19,3 & & $10,7^{*}$ & 19,3 \\
$0,40-0,50$ & $12,0^{*}$ & 16,0 & & $9,3^{*}$ & 14,7 \\
$0,50-0,60$ & 9,3 & 13,3 & & $8,0^{*}$ & 13,3 \\
$0,60-0,70$ & $8,0^{*}$ & 13,3 & & $8,0^{*}$ & 12,0 \\
$0,70-0,80$ & $6,7^{*}$ & 10,7 & & $5,3^{*}$ & 12,0 \\
$0,80-0,90$ & 5,3 & 9,3 & & $4,0^{*}$ & 10,7 \\
$0,90-1,00$ & $4,0^{*}$ & 8,0 & & $4,0^{*}$ & 9,3 \\
\hline
\end{tabular}

*Diferença significativa pelo teste $\mathrm{t}$, a $5 \%$ de probabilidade, entre os valores no início e ao final do período chuvoso de cada ano. disponível no solo -, o que de fato foi observado neste trabalho.

RQ Lavoura e RQ Cerrado apresentaram tendências parecidas, no regime hídrico controlado, em que $\mathrm{K}^{+}$ migrou para camadas inferiores (Tabela 6). Parte do potássio disponível pode ter migrado lateralmente, visto que não houve diferença significativa entre $K_{\text {int }} \mathrm{e}$ $\mathrm{K}_{\text {ext }}$ nas camadas $0,10-0,20,0,40-0,50$ e $0,60-0,70 \mathrm{~m}$, para RQ Lavoura; nem nas camadas 0,20-0,30, 0,40-0,50 e 0,90-1,00 m, para RQ Cerrado. Porém, a mobilidade vertical do nutriente foi maior que a provável mobilidade lateral, em razão do significativo efeito de fluxo de massa decorrente da percolação de água pelo perfil (Ernani et al., 2007).

Assim como no experimento com regime hídrico natural, os maiores níveis de $\mathrm{MO}$ foram observados em RQ Lavoura, os quais possivelmente estiveram associados aos maiores teores de $\mathrm{K}^{+}$nas camadas superficiais. A mobilidade do íon potássio diminui com o aumento da densidade de cargas negativas nos coloides do solo (Ernani et al., 2007), o que, consequentemente, diminui sua lixiviação pelo perfil (Duarte et al., 2013). Portanto, nas camadas em que os teores de MO foram maiores que $10 \mathrm{~g} \mathrm{~kg}^{-1}$ (Tabela 6), os teores de $\mathrm{K}^{+}$retido foram maiores, o que confirma o importante papel da MO na retenção do elemento no solo.

Os valores médios de $\mathrm{K}^{+}$no regime hídrico controlado $\left(\mathrm{K}_{\text {int }}\right)$ e no regime hídrico natural $\left(\mathrm{K}_{\text {calhas }}\right)$ estão dispostos na Tabela 7. Na comparação entre os dois regimes, não foram observadas diferenças significativas em RQ Cerrado, e diferenças significativas apenas para as profundidades $0,10-0,20,0,30-0,40$ e 0,90-1,00 m, em RQ Lavoura. Esses resultados

Tabela 4. Teores de areia, silte, argila, matéria orgânica (MO) e pH em Neossolo Quartzarênico sob cultivo de cana-deaçúcar e sob Cerrado, ao término do experimento, em abril de 2013.

\begin{tabular}{|c|c|c|c|c|c|c|c|c|c|c|}
\hline \multirow{3}{*}{$\begin{array}{l}\text { Camada } \\
\text { (m) }\end{array}$} & \multicolumn{5}{|c|}{ Lavoura } & \multicolumn{5}{|c|}{ Cerrado } \\
\hline & Areia & Silte & Argila & $\mathrm{MO}$ & \multirow[t]{2}{*}{$\mathrm{pH}$} & Areia & Silte & Argila & MO & \multirow[t]{2}{*}{$\mathrm{pH}$} \\
\hline & \multicolumn{4}{|c|}{----------------------- $\left(\mathrm{g} \mathrm{kg}^{-1}\right)$--------------------- } & & \multirow{2}{*}{\multicolumn{5}{|c|}{$\frac{1}{902} 3800$}} \\
\hline $0,0-0,10$ & 898 & 22 & 80 & 21,0 & 5,7 & & & & & \\
\hline $0,10-0,20$ & 900 & 20 & 80 & 19,0 & 5,5 & 918 & 22 & 60 & 15,0 & 4,7 \\
\hline $0,20-0,30$ & 892 & 28 & 80 & 15,0 & 5,4 & 908 & 32 & 60 & 12,0 & 4,5 \\
\hline $0,30-0,40$ & 892 & 28 & 80 & 10,0 & 5,4 & 922 & 18 & 60 & 9,0 & 4,3 \\
\hline $0,40-0,50$ & 892 & 28 & 80 & 9,0 & 5,0 & 912 & 28 & 60 & 9,0 & 4,3 \\
\hline $0,50-0,60$ & 882 & 28 & 90 & 8,0 & 5,0 & 912 & 28 & 60 & 8,0 & 4,2 \\
\hline $0,60-0,70$ & 882 & 28 & 90 & 7,0 & 4,9 & 912 & 28 & 60 & 8,0 & 4,3 \\
\hline $0,70-0,80$ & 870 & 30 & 100 & 7,0 & 4,8 & 900 & 20 & 80 & 8,0 & 4,3 \\
\hline $0,80-0,90$ & 860 & 20 & 120 & 6,0 & 4,7 & 890 & 10 & 100 & 8,0 & 4,4 \\
\hline $0,90-1,00$ & 860 & 20 & 120 & 6,0 & 4,7 & 890 & 10 & 100 & 7,0 & 4,4 \\
\hline
\end{tabular}


indicam que a movimentação de $\mathrm{K}^{+}$em solos sem ação antrópica (vegetação de cerrado) pode ser estudada em experimentos de campo com regime hídrico controlado;

Tabela 5. Valores médios de $\mathrm{K}^{+}\left(\mathrm{mg} \mathrm{dm}^{-3}\right)$ no experimento com regime de chuva natural, em Neossolo Quartzarênico sob lavoura de cana-de-açúcar e vegetação de Cerrado, no início (novembro) e ao final (abril) do período chuvoso.

\begin{tabular}{lccccc}
\hline \multirow{2}{*}{$\begin{array}{l}\text { Camada } \\
(\mathrm{m})\end{array}$} & \multicolumn{2}{c}{ Novembro 2013 } & & \multicolumn{2}{c}{ Abril 2014 } \\
\cline { 2 - 3 } \cline { 5 - 6 } & Lavoura & Cerrado & & Lavoura & Cerrado \\
\hline $0,0-0,10$ & $40,7^{*}$ & 19,3 & & $51,0^{*}$ & 38,7 \\
$0,10-0,20$ & $24,7^{*}$ & 14,7 & & $31,3^{*}$ & 26,0 \\
$0,20-0,30$ & $20,0^{*}$ & 12,0 & & 26,0 & 21,3 \\
$0,30-0,40$ & 13,3 & 10,7 & & 19,3 & 19,3 \\
$0,40-0,50$ & $12,0^{*}$ & 9,3 & & 16,0 & 14,7 \\
$0,50-0,60$ & 9,3 & 8,0 & & 13,3 & 13,3 \\
$0,60-0,70$ & 8,0 & 8,0 & & 13,3 & 12,0 \\
$0,70-0,80$ & 6,7 & 5,3 & & 12,0 & 12,0 \\
$0,80-0,90$ & 5,3 & 4,0 & & 9,3 & 10,7 \\
$0,90-1,00$ & 4,0 & 4,0 & & 8,0 & 9,3 \\
\hline
\end{tabular}

*Diferença significativa pelo teste $\mathrm{t}$, a $5 \%$ de probabilidade, entre os valores de Neossolo Quartzarênico sob lavoura e sob Cerrado. e que a área convertida em lavoura de cana-de-açúcar foi sensível ao regime hídrico adotado.

Tabela 7. Comparação entre valores médios de $\mathrm{K}^{+}(\mathrm{mg}$ $\left.\mathrm{dm}^{-3}\right)$ no experimento com regime hídrico controlado $\left(\mathrm{K}_{\mathrm{int}}\right)$ e natural ( $\mathrm{K}_{\text {calhas }}$ ), para Neossolo Quartzarênico sob cultivo da cana-de-açúcar e sob vegetação de Cerrado ${ }^{(1)}$.

\begin{tabular}{lccccc}
\hline \multirow{2}{*}{$\begin{array}{l}\text { Camada } \\
(\mathrm{cm})\end{array}$} & \multicolumn{2}{c}{ Lavoura } & & \multicolumn{2}{c}{ Cerrado } \\
\cline { 2 - 3 } \cline { 5 - 6 } & $\mathrm{K}_{\text {int }}$ & $\mathrm{K}_{\text {calhas }}$ & & $\mathrm{K}_{\text {int }}$ & $\mathrm{K}_{\text {calhas }}$ \\
\hline $0,0-0,10$ & $51,0 \mathrm{a}$ & $51,0 \mathrm{a}$ & & $40,0 \mathrm{a}$ & $38,7 \mathrm{a}$ \\
$0,10-0,20$ & $41,3 \mathrm{a}$ & $31,3 \mathrm{~b}$ & & $29,3 \mathrm{a}$ & $26,0 \mathrm{a}$ \\
$0,20-0,30$ & $33,7 \mathrm{a}$ & $26,0 \mathrm{a}$ & & $24,0 \mathrm{a}$ & $21,3 \mathrm{a}$ \\
$0,30-0,40$ & $28,0 \mathrm{a}$ & $19,3 \mathrm{~b}$ & & $22,7 \mathrm{a}$ & $19,3 \mathrm{a}$ \\
$0,40-0,50$ & $22,0 \mathrm{a}$ & $16,0 \mathrm{a}$ & & $17,3 \mathrm{a}$ & $14,7 \mathrm{a}$ \\
$0,50-0,60$ & $16,0 \mathrm{a}$ & $13,3 \mathrm{a}$ & & $16,0 \mathrm{a}$ & $13,3 \mathrm{a}$ \\
$0,60-0,70$ & $14,7 \mathrm{a}$ & $13,3 \mathrm{a}$ & & $13,3 \mathrm{a}$ & $12,0 \mathrm{a}$ \\
$0,70-0,80$ & $12,0 \mathrm{a}$ & $12,0 \mathrm{a}$ & & $13,3 \mathrm{a}$ & $12,0 \mathrm{a}$ \\
$0,80-0,90$ & $12,0 \mathrm{a}$ & $9,3 \mathrm{a}$ & & $10,7 \mathrm{a}$ & $10,7 \mathrm{a}$ \\
$0,90-1,00$ & $12,0 \mathrm{a}$ & $8,0 \mathrm{~b}$ & & $8,0 \mathrm{a}$ & $9,3 \mathrm{a}$ \\
\hline
\end{tabular}

${ }^{(1)}$ Médias seguidas por letras iguais, entre os valores de $\mathrm{K}^{+}$no interior do anel interno $\left(\mathrm{K}_{\mathrm{int}}\right)$ do experimento com regime controlado e no interior das calhas $\left(\mathrm{K}_{\text {calhas }}\right)$, no regime hídrico natural, não diferem pelo teste $\mathrm{t}$, a $5 \%$ de probabilidade.

Tabela 6. Valores médios de $\mathrm{K}^{+}\left(\mathrm{mg} \mathrm{dm}^{-3}\right)$, $\mathrm{pH}$ e matéria orgânica no experimento com regime de chuva controlada, após as amostragens: testemunha $\left(\mathrm{K}_{\text {test }}\right)$; na parte interna do anel interno $\left(\mathrm{K}_{\text {int }}\right)$; na parte externa do anel interno $\left(\mathrm{K}_{\text {ext }}\right)$; e fora do anel externo $\left(\mathrm{K}_{\text {fora }}\right)$, em Neossolo Quartzarênico sob cultivo de cana-de-açúcar e sob vegetação de Cerrado ${ }^{(1)}$.

\begin{tabular}{|c|c|c|c|c|c|c|}
\hline $\begin{array}{l}\text { Camada } \\
(\mathrm{m})\end{array}$ & $K_{\text {int }}$ & $\mathrm{K}_{\mathrm{ext}}$ & $\mathrm{K}_{\text {fora }}$ & $\mathrm{K}_{\text {test }}$ & $\mathrm{pH}$ & $\begin{array}{c}\mathrm{MO} \\
\left(\mathrm{g} \mathrm{dm}^{3}\right)\end{array}$ \\
\hline & \multicolumn{6}{|c|}{ Lavoura } \\
\hline $0,0-0,10$ & $51,0 \mathrm{a}$ & $36,0 \mathrm{~b}$ & $37,3 b$ & $39,3 b$ & 5,3 & 18,0 \\
\hline $0,10-0,20$ & $41,3 \mathrm{a}$ & $32,0 \mathrm{ab}$ & $29,7 b$ & $30,7 b$ & 5,2 & 16,0 \\
\hline $0,20-0,30$ & $33,7 \mathrm{a}$ & $25,3 b$ & $17,3 \mathrm{c}$ & $17,3 \mathrm{bc}$ & 5,2 & 14,0 \\
\hline $0,30-0,40$ & $28,0 \mathrm{a}$ & $21,3 b$ & $16,0 \mathrm{~b}$ & $14,7 \mathrm{~b}$ & 5,4 & 10,0 \\
\hline $0,40-0,50$ & $22,0 \mathrm{a}$ & $15,3 \mathrm{ab}$ & $11,3 b$ & $10,7 b$ & 5,4 & 7,0 \\
\hline $0,50-0,60$ & $16,0 \mathrm{a}$ & $13,3 b$ & $11,3 \mathrm{bc}$ & $8,0 \mathrm{c}$ & 5,2 & 7,0 \\
\hline $0,60-0,70$ & $14,7 \mathrm{a}$ & $13,3 \mathrm{a}$ & $9,3 \mathrm{bc}$ & $8,0 \mathrm{c}$ & 5,0 & 5,0 \\
\hline $0,70-0,80$ & $12,0 \mathrm{a}$ & $9,3 b$ & $8,0 \mathrm{~b}$ & $8,0 \mathrm{~b}$ & 4,9 & 5,0 \\
\hline $0,80-0,90$ & $12,0 \mathrm{a}$ & $9,3 b$ & $6,7 b$ & $5,3 \mathrm{~b}$ & 4,7 & 5,0 \\
\hline \multirow[t]{2}{*}{$0,90-1,00$} & $12,0 \mathrm{a}$ & $8,0 \mathrm{~b}$ & $4,0 \mathrm{c}$ & $4,0 \mathrm{c}$ & 4,7 & 5,0 \\
\hline & \multicolumn{6}{|c|}{ Cerrado } \\
\hline $0,0-0,10$ & $40,0 \mathrm{a}$ & $22,7 b$ & $22,7 b$ & $20,7 b$ & 4,73 & 14,0 \\
\hline $0,10-0,20$ & $29,3 \mathrm{a}$ & $17,3 b$ & $17,3 \mathrm{bc}$ & $16,0 \mathrm{c}$ & 4,87 & 12,0 \\
\hline $0,20-0,30$ & $24,0 \mathrm{a}$ & $18,0 \mathrm{ab}$ & $13,3 b$ & $13,3 b$ & 4,70 & 12,0 \\
\hline $0,30-0,40$ & $22,7 \mathrm{a}$ & $16,0 \mathrm{~b}$ & $10,7 \mathrm{c}$ & $12,0 \mathrm{c}$ & 4,43 & 9,0 \\
\hline $0,40-0,50$ & $17,3 \mathrm{a}$ & $14,7 \mathrm{ac}$ & $9,3 b$ & $10,7 \mathrm{c}$ & 4,67 & 6,0 \\
\hline $0,50-0,60$ & $16,0 \mathrm{a}$ & $12,0 \mathrm{~b}$ & $8,0 \mathrm{c}$ & $8,0 \mathrm{c}$ & 4,70 & 4,0 \\
\hline $0,60-0,70$ & $13,3 \mathrm{a}$ & $8,0 \mathrm{bd}$ & $6,7 \mathrm{c}$ & $6,7 \mathrm{~cd}$ & 4,73 & 3,0 \\
\hline $0,70-0,80$ & $13,3 \mathrm{a}$ & $8,0 \mathrm{~b}$ & $6,7 \mathrm{c}$ & $4,0 \mathrm{c}$ & 4,73 & 3,0 \\
\hline $0,80-0,90$ & $10,7 \mathrm{a}$ & $8,0 \mathrm{~b}$ & $4,0 \mathrm{c}$ & $4,0 \mathrm{c}$ & 4,93 & 4,0 \\
\hline $0,90-1,00$ & $8,0 \mathrm{a}$ & $8,0 \mathrm{a}$ & $4,0 \mathrm{~b}$ & $4,0 \mathrm{~b}$ & 4,97 & 4,0 \\
\hline
\end{tabular}

${ }^{(1)}$ Médias seguidas de letras iguais, nas linhas, não diferem a 5\% de probabilidade. 


\section{Conclusões}

1. Independentemente do uso do solo, o $\mathrm{K}^{+}$apresenta rápida movimentação pelo perfil de Neossolo Quartzarênico.

2. A área sob lavoura de cana-de-açúcar apresenta maior conteúdo de matéria orgânica do solo, maior $\mathrm{pH}$ e, consequentemente, maior capacidade de retenção do $\mathrm{K}^{+}$nas camadas superficiais do perfil, do que a área sob cerrado.

3. Na área sob lavoura, o estudo da movimentação de $\mathrm{K}^{+}$pelo perfil do Neossolo Quartzarênico é influenciado pelo regime hídrico adotado; enquanto que, na área sob cerrado, não.

\section{Agradecimentos}

Ao Conselho Nacional de Desenvolvimento Científico e Tecnológico (CNPq) e à Coordenação de Aperfeiçoamento de Pessoal de Ensino Superior (Capes), por concessão de bolsa; à Empresa BrasilAgro, do Estado de Goiás, pela disponibilização da área para estudo e à Embrapa Solos pelo auxílio logístico e desenvolvimento do trabalho.

\section{Referências}

ARAÚJO, R.; GOEDERT, W.J.; LACERDA, M.P.C. Qualidade de um solo sob diferentes usos e sob Cerrado nativo. Revista Brasileira de Ciência do Solo, v.31, p.1099-1108, 2007. DOI: 10.1590/S0100-06832007000500025.

BARBAlHO, M.G. da S.; SILVA, A.A.; CASTRO, S.S. de. A expansão da área de cultivo da cana-de-açúcar na região sul do estado de Goiás de 2001 a 2011. Revista Brasileira de Ciências Ambientais, n.29, p.98-110, 2013.

CAMPOS, L.P.; LEITE, L.F.C.; MACIEL, G.A.; IWATA, B. de F.; NÓBREGA, J.C.A. Atributos químicos de um Latossolo Amarelo sob diferentes sistemas de manejo. Pesquisa Agropecuária Brasileira, v.46, p.1681-1689, 2011. DOI: 10.1590/S0100204X2011001200014.

CARNEIRO, M.A.C.; SOUZA, E.D. de; REIS, E.F. dos; PEREIRA, H.S.; AZEVEDO, W.R. Atributos físicos, químicos e biológicos de solo de Cerrado sob diferentes sistemas de uso e manejo. Revista Brasileira de Ciência do Solo, v.33, p.147-157, 2009. DOI: 10.1590/S0100-06832009000100016.

CERRI, C.C.; FELLER, C.; CHAUVEL, A. Evolução das principais propriedades de um latossolo vermelho escuro após desmatamento e cultivo por doze e cinquenta anos com cana-deaçúcar. Cahiers Orstom. Pédologie, v.26, p.37-50, 1991.

CLAESSEN, M.E.C. (Org.). Manual de métodos de análise de solo. 2.ed. rev. e atual. Rio de Janeiro: Embrapa-CNPS, 1997. 212p. (EMBRAPA-CNPS. Documentos, 1).
DUARTE, I.N.; PEREIRA, H.S.; KORNDÖRFER, G.H. Lixiviação de potássio proveniente do termopotássio. Pesquisa Agropecuária Tropical, v.43, p.195-200, 2013. DOI: 10.1590/ s1983-40632013000200003.

ERNANI, P.R.; BAYER, C.; ALMEIDA, J.A. de; CASSOL, P.C. Mobilidade vertical de cátions influenciada pelo método de aplicação de cloreto de potássio em solos com carga variável. Revista Brasileira de Ciência do Solo, v.31, p.393-402, 2007. DOI: $10.1590 / \mathrm{S} 0100-06832007000200022$.

ERNANI, P.R.; MANTOVANI，A.; SCHEIDT, F.R.; NESI, C. Mobilidade de nutrientes em solos ácidos decorrentes da aplicação de cloreto de potássio e calcário. In: CONGRESSO BRASILEIRO DE CIÊNCIA DO SOLO, 29., 2003, Ribeirão Preto. Solo: alicerce dos sistemas de produção: [anais]. Ribeirão Preto: Unesp: Sociedade Brasileira de Ciência do Solo, 2003. CDROM.

FRAZÃO, L.A.; PICCOLO, M. de C.; FEIGL, B.J.; CERRI, C.C.; CERRI, C.E.P. Inorganic nitrogen, microbial biomass and microbial activity of a sandy Brazilian Cerrado soil under diferent land uses. Agriculture, Ecosystems and Environment, v.135, p.161-167, 2010. DOI: 10.1016/j.agee.2009.09.003.

FRAZÃO, L.A.; PICCOLO, M. de C.; FEIGL, B.J.; CERRI, C.C.; CERRI, C.E.P. Propriedades químicas de um Neossolo Quartzarênico sob diferentes sistemas de manejo no Cerrado mato-grossense. Pesquisa Agropecuária Brasileira, v.43, p.641648, 2008. DOI: 10.1590/S0100-204X2008000500012.

GOVERS, G.; VANDAELE, K.; DESMET, P.; POESEN, J.; BUNTE, $K$. The role of tillage in soil redistribution on hillslopes. European Journal of Soil Science, v.45, p.469-478, 1994. DOI: 10.1111/j.1365-2389.1994.tb00532.x.

LYRA, M.R.C.C.; ROLIM, M.M.; SILVA, J.A.A. da. Topossequência de solos fertigados com vinhaça: contribuição para a qualidade das águas do lençol freático. Revista Brasileira de Engenharia Agrícola e Ambiental, v.7, p.525-532, 2003. DOI: 10.1590/S1415-43662003000300020.

MASCARENHAS, H.A.A.; BULISANI, E.A.; MIRANDA, M.A.C. de; BRAGA, N.R.; PEREIRA, J.C.V.N.A. Deficiência de potássio em soja no Estado de São Paulo: melhor entendimento do problema e possíveis soluções. O Agronômico, v.40, p.34-43, 1988.

MEURER, E.J.; BISSANI, C.A.; SELBACH, P.A. Poluentes do solo e do ambiente. In: MEURER, E.J. (Ed.). Fundamentos de química do solo. Porto Alegre: Genesis, 2000. v.1, p.151-168.

NEVES, L.S. das; ERNANI, P.R; SIMONETE, M.A. Mobilidade de potássio em solos decorrente da adição de doses de cloreto de potássio. Revista Brasileira de Ciência do Solo, v.33, p.25-32, 2009. DOI: 10.1590/S0100-06832009000100003.

OLIVEIRA, L.F.C. de; MARTINEZ, M.A.; PRUSKI, F.F.; RUIZ, H.A.; LIMA, L.A. Transporte de solutos no solo e no escoamento superficial: I - desenvolvimento do modelo e simulação do movimento de água e escoamento superficial. Revista Brasileira de Engenharia Agrícola e Ambiental, v.4, p.63-69, 2000. DOI: 10.1590/S1415-43662000000100012.

ORLANDO FILHO, J.; SILVA, G.M.A.; LEME, E.J.A. Utilização agrícola dos resíduos da agroindústria canavieira. In: ORLANDO 
FILHO, J. (Coord.). Nutrição e adubação da cana-de-açúcar no Brasil. Piracicaba: Planalsucar, 1983. p.227-264.

PADILLA, I.Y.; JIM YEH, T.-C.; CONKLIN, M.H. The effect of water content on solute transport in unsaturated porous media. Water Resources Research, v.35, p.3303-3313, 1999. DOI: 10.1029/1999WR900171.

RAMOS, J.C. Erosão hídrica influenciada pelo cultivo, cobertura do solo por resíduos culturais e rugosidade superficial, em um Cambissolo Húmico. 2013. 84p. Dissertação (Mestrado) - Universidade do Estado de Santa Catarina, Lages.

SILVA, A.A.; MIZIARA, F. Avanço do setor sucroalcooleiro e expansão da fronteira agrícola em Goiás. Pesquisa Agropecuária Tropical, v.41, p.399-407, 2011. DOI: 10.5216/pat.v41i3.11054.

SILVA, F. de A.S. e; AZEVEDO, C.A.V. de. Principal Components Analysis in the Software Assistat-Statistical Attendance. In: WORLD CONGRESS ON COMPUTERS IN AGRICULTURE AND NATURAL RESOURCES, 7., 2009, Reno. [Anais]. St. Joseph: American Society of Agricultural and Biological Engineers, 2009.
SILVA, M.A.G.; BOARETTO, A.E.; MURAOKA, T.; FERNANDES, H.G.; GRANJA, F.A.; SCIVITTARO, W.B. Efeito do nitrogênio e potássio na nutrição do pimentão cultivado em ambiente protegido. Revista Brasileira de Ciência do Solo, v.25, p.913-922, 2001. DOI: 10.1590/S010006832001000400014.

SILVA, M.A.S. da; GRIEBELER, N.P.; BORGES, L.C. Uso de vinhaça e impactos nas propriedades do solo e lençol freático. Revista Brasileira de Engenharia Agrícola e Ambiental, v.11, p.108-114, 2007. DOI: 10.1590/S1415-43662007000100014.

WERLE, R.; GARCIA, R.A.; ROSOLEM, C.A. Lixiviação de potássio em função da textura e da disponibilidade do nutriente no solo. Revista Brasileira de Ciência do Solo, v.32, p.22972305, 2008. DOI: 10.1590/S0100-06832008000600009.

ZUO, X.; ZHAO, H.; ZHAO, X.; ZHANG, T.; GUO, Y.; WANG, S.; DRAKE, S. Spatial pattern and heterogeneity of soil properties in sand dunes under grazing and restoration in Horqin Sandy Land, Northern China. Soil and Tillage Research, v.99, p.202212, 2008. DOI: 10.1016/j.still.2008.02.008.

Recebido em 31 de agosto de 2015 e aprovado em 4 de julho de 2016 